Journal of Case Reports 2020;10(4):226-228

\title{
Orofacial Manifestations of Sturge-Weber Syndrome
}

\author{
Ramneek Bansal $^{1}$, Divye Malhotra ${ }^{1}$, Amit Goel $^{2}$, Shubh Karmanjit Singh Bawa ${ }^{2}$, Parul Sharma ${ }^{2}$, Steffy Bansal $^{3}$ \\ Departments of ${ }^{1}$ Oral Surgery and ${ }^{2}$ Oral Periodontics, Himachal Dental College, Sundernagar, Mandi, Himachal Pradesh; ${ }^{3}$ Private \\ Practice, Himachal Pradesh, India.
}

\section{Corresponding Author:}

Dr. Ramneek Bansal

Email: ramneekkumar70@yahoo.co.in

This is an Open Access article distributed under the terms of the Creative Commons Attribution License (creativecommons.org/ licenses/by/3.0).

Received

Accepted

Published

May 29, 2020

August 30, 2020

October 30,2020

\begin{abstract}
Background: Sturge-Weber syndrome is a rare neurocutaneous condition, also known as angiomatosis of the encephalotrigeminals. It has varied systemic and oral manifestations, and the challenge for a dental practitioner is to manage oral condition in such a case. Case Report: We hereby report Sturger-Weber syndrome with dermatological and intraoral manifestations. The lesion had an uneventful healing following gingivectomy and flap surgery. Conclusion: Gingivectomy and flap surgery is an option to manage gingival overgrowth.
\end{abstract}

Keywords: Angiomatosis, Dentists, Gingival Overgrowth, Gingivectomy, Sturge-Weber Syndrome.

\section{Introduction}

Congenital deformation, while uncommon, is a big concern for both the patient and their families. Sturge-Weber angiomatosis is a rare, non-hereditary developmental condition that is characterized by a hamartomatous vascular proliferation involving the tissues of the eye, brain and face at different times [1]. Ipsilateral angiomatous lesion of face is sometimes accompanied by angiomatous lesions of skin, jaw and oral cavity. Sturge-Weber syndrome (SWS) is a neuro-cutaneous disorder characterized by the presence of a facial portwine stain, a leptomeningeal angioma, and occular abnormalities, most commonly glaucoma [2]. This syndrome basically belongs to group of disorders collectively known as phakomatoses (mother-spot diseases). Angiomatosis and skin changes follow the maxillary and ophthalmic trigeminal nerve distribution [5].

Oral manifestations observed in about 38\% of the cases can include hemangiomatous lesion [6]. Gingival overgrowth is the most common oral manifestation restricted to the ipsilateral maxilla or mandible [7]. This paper presents a case report of a Sturge-Weber syndrome patient distinguished by port-wine stains and ipsilateral gingival enlargement manifestation.

\section{Case Report}

A 45 year-old woman reported to the Department of Periodontics with a complaint of swelling in the lower front gum region since 3 months. Clinically there were multilobed gingival swellings in the lower right anterior region between central incisor and canine (41 and 43) and mobile anterior teeth [Fig.1]. The swellings were red and shiny

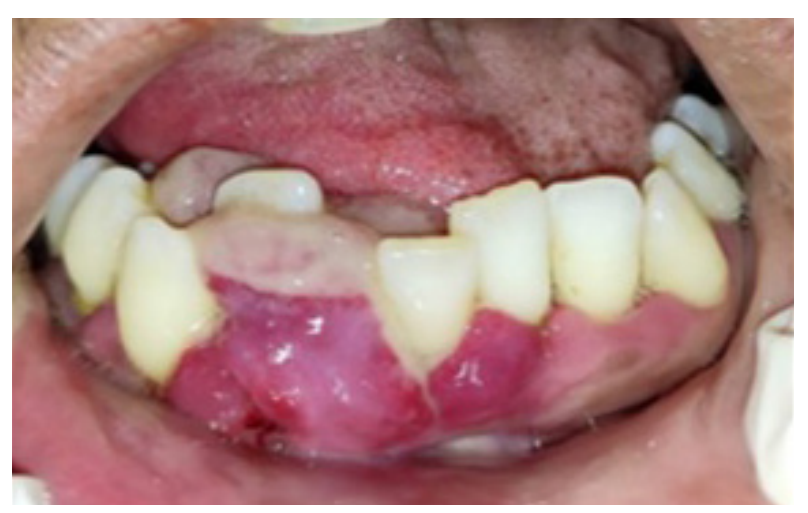

Fig.1: Multilobed gingival swellings on pre-operative view. 
in appearance measuring about $8 \mathrm{~mm}$ in width extending from mesial surface of central incisor to the mesial half of canine on the labial side and were extending on the lingual side of incisors [Fig.2,3]. These swellings were connected at the interdental area of central incisor and canine. On palpation the swelling was a pedunculated mass, soft and easily movable from the base. Lesion showed considerable amount of bleeding on probing.

Extra-oral bluish red discoloration (port wine stain) was present on right side of face which was asymmetrical [Fig.4]. History revealed that the stain was present since childhood. Intraoral RadioVisioGraphy (RVG) was taken to assess the bone involvement. Radiograph revealed bone loss till the apical portions of roots of 41,42 [Fig.5]. Local anesthesia was given to patient and as the lesion had a pedunculated base with bone loss w.r.t 41,42; excisional biopsy was carried out carefully followed by bony curettage along with extraction of 41,42 . Histopathological examination revealed numerous endothelium lined spaces, abundant fibroblasts, collagen fibers, and polymorphonuclear leucocytes revealing features of pyogenic granuloma. At the end of 1 month, the lesion had uneventful healing [Fig.6]. Three months follow-up was quite satisfactory and there was no evidence of any recurrence [Fig.7].

\section{Discussion}

In the present time, the number of anomalies is decreasing, but even the few cases found become disturbing. It has been seen that majority of hemangiomas subside at 10-15 years of age but in few cases they have been found to affect the esthetic of patient for longer durations as seen in the above case. The port-wine nevus is located in the face, particularly on the right side of the face, according to Inan and Marcus [8], and detected in $90 \%$ of cases.

$$
\text { Sturge Weber syndrome or }
$$
encephalotrigeminal angiomatosis is a disease with hemangiomatosis, therefore, such granulomatous

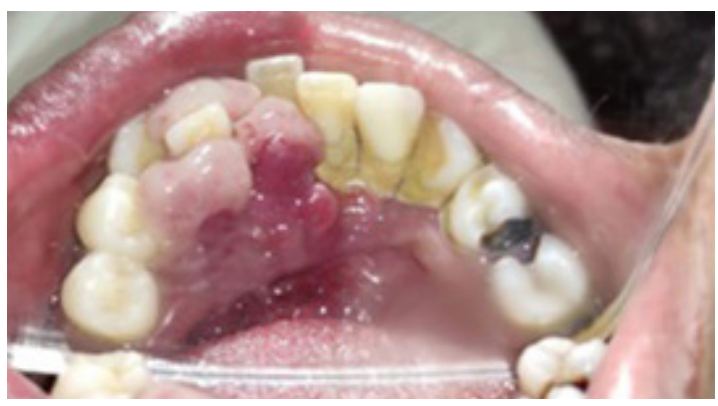

Fig.2: Pre-operative view showing lingual extension of the lesion.

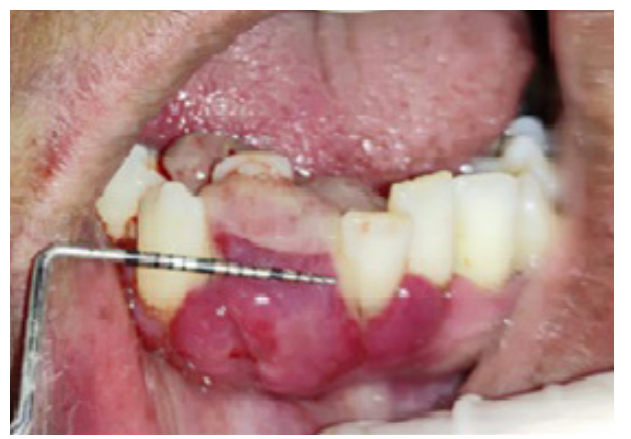

Fig.3: Pre-operative view showing width of the lesion.

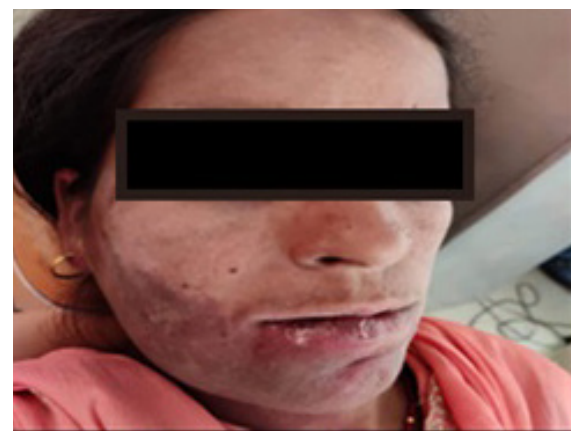

Fig.4: Extra-oral view showing port wine stains.

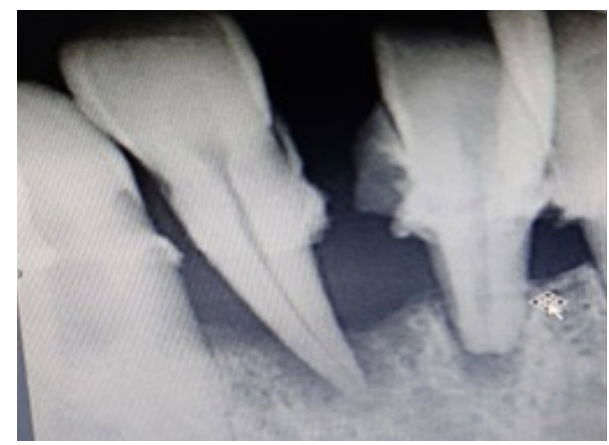

Fig.5: $R V G$ showing bone loss till the apical portions of roots of 41,42 . 


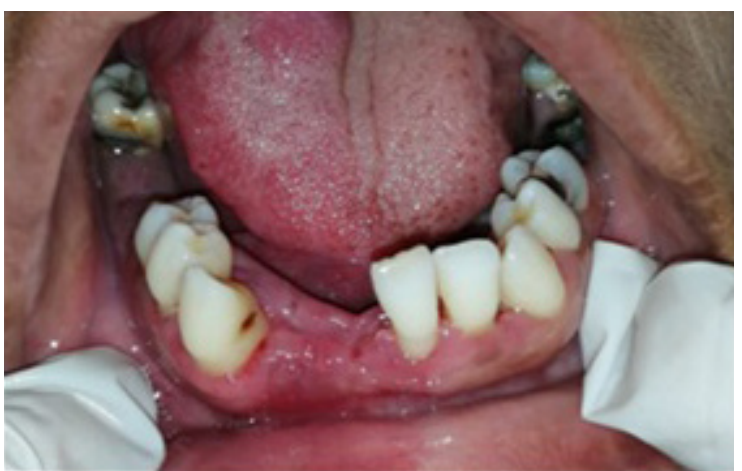

Fig.6: Post-operative view.

lesions in oral cavity are not unusual. Case has been found in accordance with Bioxeda et al. [4], distribution of port wine stains is found mainly in $2^{\text {nd }}$ division of trigeminal nerve i.e. maxillary nerve. It can also be referred to as incomplete SWS, and this patient was classified as Type II SWS only facial angiomas based on Roach scale. The gingival swelling correlated with Sturge-Weber syndrome may result from angiomatous proliferation of the gingival tissue involved, antiepileptic medication or a combination. This patient had no neurological involvement or background of anti-epileptic medication, the observed gingival overgrowth may be attributed solely to angiomatous proliferation.

\section{Conclusion}

Management of such syndromes is usually a multidisciplinary approach which involves many specialities i.e. plastic surgeon, hematologist, oral surgeon etc. Periodontal treatment includes proper manual debridement and motivating the patient to follow a strict regimen of plaque protection and surgical management. For the present case, a combination of gingivectomy and flap surgery was used to manage gingival overgrowth.

Contributors: RB was involved in manuscript writing, and patient management. DM, AG SKSB and PS reviewed the manuscript and were involved in patient management. SB provided critical inputs into the manuscript. RB will act as

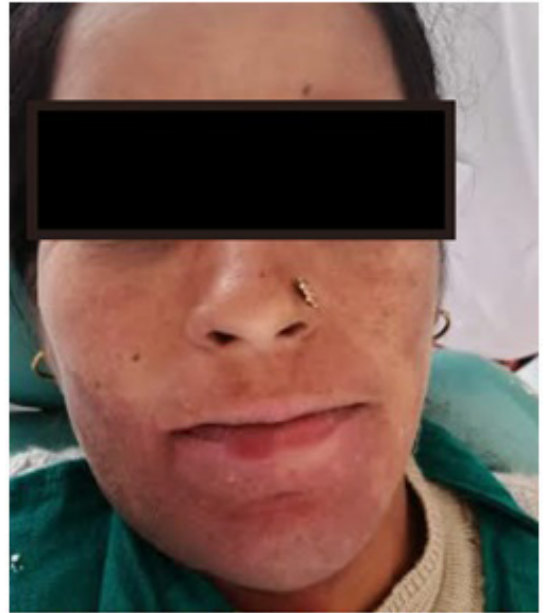

Fig.7: 3 months post-operative view.

study guarantor. All authors approved the final version of the manuscript and are responsible for all aspects of the study.

Funding: None; Competing interests: None stated.

\section{References}

1. Caiazzo A, Mehra P, Papageorge MB. The use of preoperative percutaneous transcatheter vascular occlusive therapy in the management of Sturge-Weber syndrome: Report of a case. J Oral Maxillofac Surg. 1998;56:775-778.

2. Comi AM. Sturge-Weber Syndrome. In: National Organization for Rare Disorders, editor. NORD Guide to Rare Disorders. Lippincott Williams \& Wilkins. 2003. pp. 258.

3. Zhou J, Li NY, Zhou XJ, Wang JD, Ma HH, Zhang RS. Sturge-Weber syndrome: A case report and review of literatures. Chin Med J. 2010;123:117-121.

4. Bioxeda P, de Misa RF. Facial angioma and the SturgeWeber syndrome. MedClin (Barc). 1993;101:18-19.

5. Banthia R, Banthia P, Belludi S. Sturge-Weber syndrome: A case report. J Ind Dent Assoc. 2011;5:277-278.

6. Neto FX, Junior MA, Ximenes LS, Jacob CC, Junior AG, Palheta CP, et al. Clinical features of Sturge-Weber syndrome. Arq Int Otorrinolaringol. 2008;12:565-570.

7. Arzimanoglouann AA. Sturge-Weber syndrome: Indications and results of surgery in 20 patients. Neurol. 2000;55:1472-1479.

8. Inan C, Marcus J. Sturge-Weber syndrome: report of an unusual cutaneous distribution. Brain and Development. 1999;21:68-70. 